\title{
The Optimization of the Ratio between Rotor Slot Width and Rotor Tooth Pitch to Reduce Cogging Torque in Line-Start Permanent Magnet Synchronous Motors
}

\author{
Diao Tongshan* \\ School of Electrical Engineering and Automation, \\ Qilu University of Technology, \\ Jinan, China \\ E-mail: diao-tong-shan@ 126.com \\ * Corresponding Author
}

\begin{abstract}
The finite element method and analytical method are combined to optimization of the ratio between rotor slot width and rotor tooth pitch to reduce cogging torque in linestart permanent magnet synchronous motors.Based on energy theory equation and Fourier transform, The simulation analysis results are in good agreement with the proposed method.

Keywords- Cogging torque; Simulation; line-start permanent magnet synchronous motors(LSPM); Finite element method; Electromagnetic field; analytical method
\end{abstract}

\section{INTRODUCTION}

With the continuous improvement of the permanent magnetic material, the permanent magnet motor is widely used in the high performance speed and position control system.However in permanent magnet motor, permanent magnet and armature core interactions and inevitable estate thecodont torque, resulting in torque ripple caused by vibration and noise, the system control accuracy.

Cogging torque is one of the permanent magnet motor specific problems, is the key problem in the high performance permanent magnet motor design and manufacturing must be considered and solved.

Line-start permanent magnet synchronous motors(LSPM) combines the electromagnetic of both permanent magnets and machine winding. So it is very complex inside the electromagnetic field.Another, because the permanent magnets are of magnet energy, the cogging torque is produced. The cogging torque in LSPM can cause torque ripple, which eventually led to the vibration and noise.With cogging torque an important parameter in LSPM design and to prevent any adverse effects transferred to the rotary shaft, an absolute minimum for this output parameter is essential.In order to reduce the cogging torque, many studies have been carried out and many practical feasible methods were given[1]-[6].

Some of these techniques are based on modifying the current waveforms to cancel torque pulsations for any PM motor with known electromotive force(EMF)waveform. The other techniques are based on the structural solutions. The first structural solutions consists in adapted choice of the stator winding for a given number of stator slots.Even if this solutions allow to minimize the ripple torque rate due the interaction between the stator currents and rotor magnets, it has no effect on the cogging torque since the stator slots design is chosen. As well known in PM motors cogging torque arises from the interaction between magnets and soltted iron stator. Some solutions consists to optimize the magnets pole angular span.These solutions can be achieved by introducing magnetic wedges in slots that reduces significantly the cogging torque.In fact, for a given slot pitch, there is several values of tooth width which minimize the cogging torque.A teeth-pairing design with different tooth widths as well as the teeth notching design allow to reduce the cogging torque. One of the most popular techniques that allow to reduce the cogging torque is to skew the stator lamination stack or rotor magnets. To make easier the rotor manufacturing, the rotor skewing may be done. Relatively little literature exists on the cogging torque research on rotor slot.

This paper seeks to improve the performances for LSPM based on studying its cogging torque. The paper is organized as follows. Section II depicts the generation causes of cogging torque and impact factors. In Section III, based on FEM , the model of LSPM were established and electromagnetic characters of that was analyzed by Maxwell ansoft software.Reducing the cogging torque method is described.Simulation results on $22 \mathrm{~kW}$ LSPM are provided, and finally, conclusions are drawn in Section IV.Simulation studies are carried out to verify the proposed method.

\section{ROTOR SHAPE ANALYTICAL EXPRESSION FOR COGGING TORQUE}

The design of LSPM motors must meet the requirements of some industrial applications, such as operation accuracy and stability.One of the most important constraints the mechanical shaft vibrations, especially at low speeds, that can be avoided by reducing the amplitude of torque harmonics. This can be achieved by using a wide range of techniques proposed by many researchers [7]-[9].A permanent magnet synchronous motor is studied in this paper.Based on 
energy method and Fourier expansion, the expression of cogging torque is established.

In order to simplify the theory analysis, some presumptions are given:

(a)Permanent magnets are supposed to be magnetized in radial direction.

(b) Permeability of iron core of stator and rotor is infinite.

(c)Stator slots are simplified to be rectangular.

(d)The distribution of magnetic field in air gap is one dimensional.

(e)Permeability of permanent magnet is equal to that of air. (6) The position of $\theta=0$ is located in the midline of one of the permanent magnets.

Based on above presumptions, energy method stored in the motor was approximately equal to the energy in airgap of the motor plus the energy in permanent magnet, the cogging torque $T_{\mathrm{cog}}$ is the variation of energy in the permanent magnet machines when the rotor rotates. It is the negative derivative of the coenergy $W$ with respect to the revolution angle $\alpha$. Thus, the cogging torque can be expressed as (1). In this paper, $\alpha$ is assumed to be an angle between the midline of permanent magnet and that of a tooth.

$$
T_{c o g}=-\frac{\partial W}{\partial \alpha}
$$

The energy discussed in the paper only referrers to the air-gap energy, and because of the permeability of the iron core of stator and rotor is tremendous, the energy of airgap magnetic field can be approximately regarded as (2).

$$
W=W_{\text {air }+P M}=\frac{1}{2 \mu_{0}} \int_{V} B^{2} d V
$$

Air-gap energy is $W_{\text {air }}$, which is depended on the structured dates of the motor and the relative position between the permanent magnet and the armature tooth. Where $\mu_{0}$ is the magnetic permeability of vacuum. A relative position,the distribution of magnetic flux density can be expressed as

$$
B(\theta, \alpha)=\mathrm{B}_{r}(\theta) \frac{h_{m}(\theta)}{h_{m}(\theta)+g(\theta, \alpha)}
$$

where $B_{\mathrm{r}}(\theta)$ is the residual magnetic distribution of permanent magnet along the circumference direction of air gap, $h_{\mathrm{m}}(\theta)$ the lenghth of PM in magnetization direction, $g(\theta, \alpha)$ is the distribution of effective airgap length[10-13]. Therefore, the (3) is substituted into the (2), which can be rewritten as the (4).

$$
W=\frac{1}{2 \mu_{0}} \int B_{r}^{2}(\theta)\left(\frac{h_{m}}{h_{m}+g(\theta, \alpha)}\right)^{2} d V
$$

$B_{r}^{2}(\theta)$ and $\left[h_{\mathrm{m}} /\left(\mathrm{h}_{\mathrm{m}}+\mathrm{g}(\theta, \alpha)\right]^{2}\right.$ are obtained respectively, which can give the expression of the cogging torque.Fourier expansions are (5)and (6), respectively. Here, $G_{0}$ is the initial Fourier coefficient, $G_{\mathrm{n}}$ is the $\mathrm{n}^{\text {th }}$ Fourier initial coefficient, and $\mathrm{z}$ is the number of stator slot.

$$
B_{r}^{2}(\theta)=B_{r 0}+\sum_{n=1}^{\infty} B_{r n} \cos n \frac{Q_{2}}{q_{2}} \theta
$$

$$
\left(\frac{h_{m}}{h_{m}+g(\theta, \alpha)}\right)^{2}=G_{0}+\sum_{n=1}^{\infty} G_{n} \cos n z(\theta+\alpha)
$$

(5)and (6) are substituted into (1), the cogging torque is expressed as (7)

$$
T_{c o g}(\alpha)=\frac{\pi z L_{F e}}{4 \mu_{0}}\left(\mathrm{R}_{2}^{2}-\mathrm{R}_{1}^{2}\right) \sum_{n=1}^{\infty} n G_{n} B_{r \frac{n z q_{2}}{Q_{2}}} \sin n z \alpha
$$

where $R_{2}$ is stator yoke inner diameter, $R_{1}$ is rotor outer diameter, and $L_{\mathrm{Fe}}$ is stator core axial length, $\mathrm{q}_{2}$ is number of slots per phase every pole, $\mathrm{q}_{2}$ is equal to the $\mathrm{Q}_{2} / 2 \mathrm{p}$.For $\mathrm{W}$ shaped structure, $\mathrm{n}$ is an integer,which can make $\mathrm{nzq}_{2} \mathrm{Q}_{2}$ is an integer. For IPM structure, $\mathrm{n}$ is an integer,which can make $n z / Q_{2}$ is an integer.

According to (7), only $\mathrm{nzq}_{2} \mathrm{Q}_{2}$ Fourier decomposition coefficients can make an effect on the cogging torque, therefore there is an expression below

$$
B_{r \frac{n z q_{2}}{Q_{2}}}=\mathrm{O}
$$

From (8) can be expression as below

$$
\frac{t_{w}}{t_{p}}=\frac{k Q_{2}}{n z}
$$

Rotor tooth width that meet (9) will be able to reduce the cogging torque ,because $B_{\mathrm{r}}(\theta)$ harmonics is equal to zero, $T_{\mathrm{w}}$ is the rotor tooth width, $T_{\mathrm{p}}$ is the rotor tooth pitch.

\section{FINITE ELEMENT ANALYSIS}

Different architectures of the synchronous rotor,mounted inside a conventional stator of an induction motor.The geometry of the LSPM discussed in this paper is as shown in Fig.1. The first rotor(a)is similar to a cage induction rotor with interior $\mathrm{W}$-shape permanent magnets(WPM), the second rotor(b)is known as interior permanent magnet synchronous motor(IPM). These types of motors have a larger air-gap flux density due to a higher excitation and torque than the surface mounted magnets motors.The model of WPM and IPM were established and analyzed by Maxwell ansoft software, in order to verify the correctness of the theory mentioned. A time-step finite element method was used to further analyze the influence factors of cogging torque. 


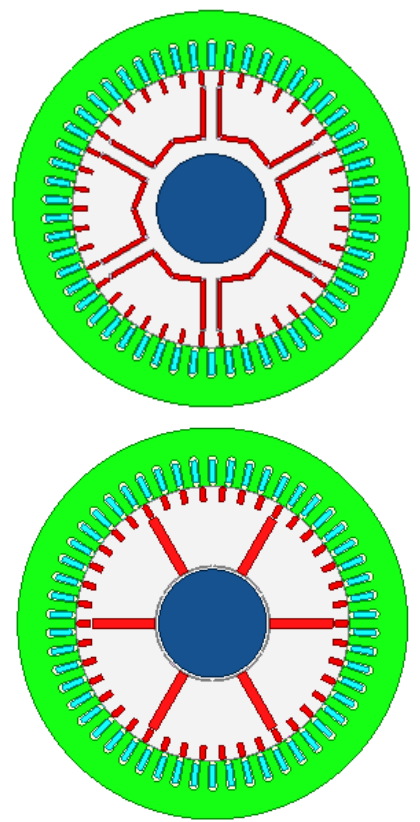

(a) WPM

(b) IPM

Figure 1. Two prototypes of LSPM

Rated power is $22 \mathrm{~kW}$, rated voltage is $380 \mathrm{~V}$, rated speed is $1000 \mathrm{r} / \mathrm{min}$, permanent magnet is made of $\mathrm{Nd}-\mathrm{Fe}$ $\mathrm{B}$, driving power is direct current power supply, and the structure of poles are tile shape and radial magnetization. The main technical parameters of motors are shown in TABLE I.

TABLE 1 Parameters of prototype

\begin{tabular}{|c|c|c|c|}
\hline Parameters & Values & Parameters & Values \\
\hline $\begin{array}{l}\text { Outer diameter of } \\
\text { stator }(\mathrm{mm})\end{array}$ & 327 & $\begin{array}{l}\text { Width per pole of } \\
\text { PM (mm) }\end{array}$ & 124 \\
\hline $\begin{array}{l}\text { Inner diameter of } \\
\text { stator }(\mathrm{mm})\end{array}$ & 230 & $\begin{array}{l}\text { Axial length of } \\
\text { PM (mm) }\end{array}$ & 220 \\
\hline $\begin{array}{l}\text { Inside diameter } \\
\text { of rotor }(\mathrm{mm})\end{array}$ & 90 & $\begin{array}{l}\text { Thickness of PM } \\
(\mathrm{mm})\end{array}$ & 6 \\
\hline Pole pairs & 6 & $\begin{array}{l}\text { Residual flux density } \\
\text { B (T) }\end{array}$ & 1.04 \\
\hline Stator slot number & 54 & $\begin{array}{l}\text { Coercive force } \mathrm{H}_{\mathrm{c}} \\
(\mathrm{kA} / \mathrm{m})\end{array}$ & 890 \\
\hline $\begin{array}{l}\text { Rotor slot } \\
\text { number }\end{array}$ & 42 & $\begin{array}{c}\text { Stack length } \mathrm{L}_{\mathrm{Fe}} \\
((\mathrm{mm}))\end{array}$ & 220 \\
\hline
\end{tabular}

The cogging torque curves under the different ratio between rotor slot mouth width and rotor tooth pitch are shown in Fig.2.and Fig.3. In this figure, a comparison shows that cogging torque is reducing,with the decreasing ratio between rotor slot mouth width and rotor tooth pitch.

Amplitude of cogging torque is shown in Fig. 2. Fig.2 shows when ratio between rotor slot mouth width and rotor tooth pitch $\left(\mathrm{T}_{\mathrm{w}} / \mathrm{T}_{\mathrm{p}}\right)$ is 0.911 , the amplitude of cogging torque is $15.02 \mathrm{Nm}, \mathrm{With} \mathrm{T}_{\mathrm{w}} / \mathrm{T}_{\mathrm{p}}$ become little, the cogging torque become little.when $\mathrm{T}_{\mathrm{w}} / \mathrm{T}_{\mathrm{p}}=0.634$, the amplitude of cogging torque is $4.93 \mathrm{Nm}$, which is weakened by $67.2 \%$.

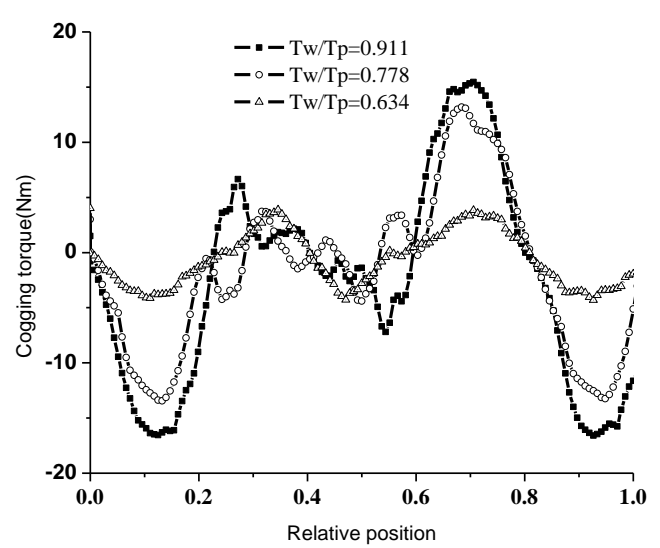

Figure 2. The comparison of cogging torque with different rotor tooth width and tooth pitch(WPM)

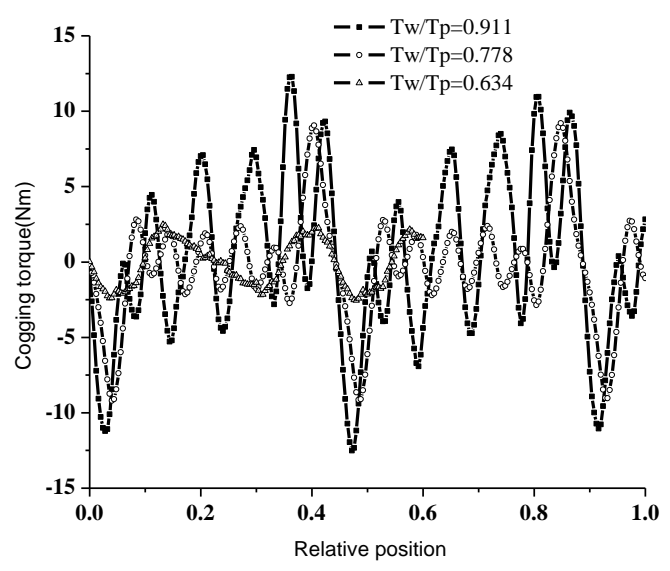

Figure3. The comparison of cogging torque with different rotor tooth width and tooth pitch(IPM)

Amplitude of cogging torque is shown in Fig.3. Fig.3 shows when ratio between rotor slot mouth width and rotor tooth pitch $\left(\mathrm{T}_{\mathrm{w}} / \mathrm{T}_{\mathrm{p}}\right)$ is 0.911 , the amplitude of cogging torque is $12.51 \mathrm{Nm}$; With $\mathrm{T}_{\mathrm{w}} / \mathrm{T}_{\mathrm{p}}$ become little ,cogging torque become little, when $\mathrm{T}_{\mathrm{w}} / \mathrm{T}_{\mathrm{p}}=0.634$, the amplitude of cogging torque is $2.48 \mathrm{Nm}$, which is weakened by $80.2 \%$.

Simulation results show that the optimization of the ratio between rotor slot width and rotor tooth pitch can be reduced cogging torque in LSPM.Selecting suitable rotor tooth width $\left(T_{\mathrm{w}}\right)$ and the rotor tooth pitch $\left(T_{\mathrm{p}}\right)$,the cogging torque will be significantly decreased.Width of slot mouth can be changed by the adopting magnetic slot wedge method.The adopting magnetic slot wedge makes the magnetic conductance become more uniform distribution, in order to reduce the cogging torque. However the conduction performance of magnetic slot wedge material is not very good, the cogging torque is a limited reduction. The closed slot method makes width of slot mouth become zero. Material of slot mouth is equal to material of slot tooth, therefore the closed slot method can more effectively reduce the cogging torque of permanent magnet synchronous compared with the adopting magnetic slot wedge. 
In a word, the reducing the ratio between rotor slot width and rotor tooth pitch, the adopting magnetic slot wedge and the closed slot can effectively reduce the cogging torque of LSPM. However, these methods easily give rise to complex structure, increase leakage reactance and adverse influence the dynamic performance for LSPM.

The reducing the ratio between rotor slot width and rotor tooth pitch is a very effective method to decrease the cogging torque of LSPM. In theory, rotor slot become wider, which makes magnetic flux density of air gap become a constant, in order to completely reduce cogging torque.

\section{CONCLUSIONS}

In this paper, rotor slot shapes were optimized to minimize the cogging torque for LSPM. For the shape optimization of the rotor slot, we used a analytical method based on Maxwell tensor method. Our approach yielded clear optimized rotor slot configurations. The according to the analytical result, the optimization of the ratio between rotor slot width and rotor tooth pitch can be get. Cogging torque and torque ripple were remarkably decreased in the optimized models.

\section{REFERENCES}

[1] X. H. Wang, Y. B. Yang and D. J. Fu, "Study of cogging torque in surface-mounted permanent magnet motors with energy method," Journal of Magnetism and Magnetic Materials,267 (1) (2003) 8085.

[2] Y. B. Yang, X. H. Wang and T. T. Ding, "Analysis of the optimization of the pole arc combination to reduce the cogging torque in PM motors," Proceeding of the CSEE, 27 (6)(2007) 7-11.
[3] Liu X, Zhu Z Q. "Electromagnetic performance of novel variable flux reluctance machines with DC-field coil in stator,"IEEE Trans. Magnetics, 2013, 49(2): 3020-3028.

[4] S. Shi, Q. F. Li and X. H. Wang, "Study of cogging torque in surface-mounted permanent magnet motors with energy method,"Journal of Magnetism and Magnetic Materials, 267(1) (2003) 80-85.

[5] L. Zhu, S. Z. Jiang, Z. Q. Zhu and Q. Q. Chen, "Comparison alternate analytical models for predicting cogging torque in surface mouthed permanent magnet machines," Micromotors, 43 (1) (2010) $10-16$.

[6] X. H. Wang, Y. B. Yang and T. T. Ding, "Method for reducing cogging torque by suitable selection of pole-arc coefficient in solid-rotor PM synchronous motors," Proceeding of the CSEE, 25 (15) (2005) 146-149.

[7] W. Fei, P. C. K. Luk, "A High Performance Line-start permanent magnet synchronous motor amended from a small industrial threephase induction motor," IEEE Transactions on Energy Conversion, vol. 45, No. 10, October 2009. pp. 4724-4727.

[8] C. C. Hwang, M. H. Wu and S. P. Cheng, "Influence of pole and slot combinations on cogging torque in fractional slot PM motors," Journal of magnetism and magnetic materials, 36 (12) (2006) 430432.

[9] K. Abbaszadeh, F. Rezaee Alam and S. A. Saied, "Cogging torque optimization in surface-mounted permanent-magnet motors by using design of experiment," Energy Conversion and Management, 52 (10) (2011) 3075-3082.

[10] Chai J Y, Liaw C M. "Reduction of speed ripple and vibration for switched reluctance motor drive via intelligent current profiling," IET Proc. Electr.Power Appl., 2010, 4(5): 380-396.

[11] Ahn J, Park S, Lee D. "Hybrid excitation of SRM for reduction of vibration and acoustic noise,"IEEE Trans. Industry Electronics, 2004, 51(2):374-380.

[12] Lin F, Yang S. "An approach to producing Controlled radial force in a switched reluctance motor,"IEEE Trans. Industry Electronics, 2007,54(4): 2137-2146.

[13]Wang Xiuhe. Permanent magnet motors[M]. Beijing : Press of Electric Power, 2007 : 52-54. 